\title{
ALZHEIMER'S DISEASE IS, AT LEAST IN PART, A COPPER-2 TOXICITY DISEASE
}

\author{
G.J. Brewer
}

\begin{abstract}
Developed countries have a raging epidemic of Alzheimers disease, with prevalence around $20 \%$ by age 70 . Good evidence indicates this epidemic is new, with an Alzheimer's-like dementia being rare prior to 1900. Prevalence of Alzheimer's in undeveloped countries is still quite low, around 1\%. These sets of facts strongly indicate that environmental change is causing the epidemic in developed countries. It is hypothesized here, with very good evidence, that the new environment change in developed countries is ingestion of inorganic copper, copper-2, from drinking water and supplement pills. There is good evidence that copper toxicity plays a major role in the pathogenesis of Alzheimer's, with the size of the free copper pool intimately tied to cognition and cognition loss. Studies in $\mathrm{AD}$ animal models show that tiny amounts of inorganic copper in drinking water greatly enhance Alzheimers-type pathology and memory loss. Studies in humans show that those ingesting supplement pills containing copper, if they also eat a high fat diet, suffer rapid loss of cognition. Drinking water copper, and pill copper are both divalent copper, or copper-2. A recent study shows that food copper is primarily copper-1. There is an intestinal transport system specific for copper-1, and this copper goes to the liver, and is put into safe channels. Because mammals, including humans, ingested only copper-1, their systems evolved to safely handle copper-1. With development came copper plumbing and supplement pill ingestion, and copper- 2 is now ingested. Some of it bypasses the liver, ends up in the blood free copper pool, and is toxic to cognition.
\end{abstract}

Key words: Alzheimer's disease, copper-2, copper toxicity, drinking water copper, supplement pill copper.

\section{Introduction}

Considerable evidence has been developed that copper toxicity plays an important role in Alzheimer's disease $(\mathrm{AD})$. But the puzzle has been that the brain toxicity of copper in AD causes cognition loss, while the brain toxicity of copper in Wilson's disease (WD), a disease known to be caused by copper toxicity, causes a movement disorder. This is puzzle 1. Secondly, considerable evidence has developed that inorganic copper, the divalent copper found in drinking water and supplement pills, is especially damaging to cognition and causative of $\mathrm{AD}$ in $\mathrm{AD}$ animal models, compared to the organic copper in foods. Why? This is puzzle 2.

Recently a paper was published which brings clarification and solutions to both puzzles 1 and 2 (1). Most exciting, it indicates much of the epidemic of AD can be aborted by simply stopping the ingestion of inorganic copper (divalent copper, or copper-2). This paper, which studied the speciation of copper in food, found that food copper was almost entirely monovalent

University of Michigan, USA

Corresponding Author: George J Brewer, University of Michigan, USA, brewergj@ umich.edu copper, or copper-1. This finding was very surprising, because it had always been assumed food copper was a mixture of copper-1 and copper-2, since the two valence forms make a redox doublet that allow the catalysis of many redox reactions critical to life. Apparently, after death or harvest, in the absence of oxygen transport, copper-2 is reduced to copper-1 in foods. This finding changes everything. It means that mammals, including the human, evolved ingesting only copper- 1 . In line with this, the body has a transport system for copper-1, first passing it through the liver to keep it in safe channels. No such system exists for copper-2, and some bypasses the liver, appearing immediately in the blood, where it is toxic to cognition. So this solves puzzle 2. Inorganic copper, which is copper-2, is especially toxic because it bypasses the liver. It also solves puzzle1. The diseases, $\mathrm{AD}$ and $\mathrm{WD}$, show different forms of copper toxicitybecause AD is a copper-2 toxicity disease and WD is a general copper overload disease with copper-2 playing no special role. In this review we will elaborate on these new and exciting features. 


\section{Copper Toxicity in Alzheimer's Disease}

In this section the evidence for copper toxicity in $\mathrm{AD}$ will be reviewed without reference to the valence of copper. The group in Italy led by Professor Rosanna Squitti has amassed a large amount of data showing copper toxicity is intimately involved with AD pathogenesis. They have focused on what is called the "blood free copper pool". Blood copper can be thought of as existing in two pools. The larger, comprising about $85 \%$, is copper covalently bound to the ceruloplasmin (Cp) molecule. The smaller pool, comprises copper more loosely bound to albumin and various small molecules, and is called the free copper pool. Because of its more loose binding it is available to meet tissue needs in the body. If this pool becomes expanded, as it does greatly in WD, this copper becomes toxic.

The Squitti group has shown in AD patients: 1) The free copper pool is larger than in age-matched controls $(2)$; 2) The size of the free copper pool correlates negatively with measures of cognition (3); 3) The size of the free copper pool correlates positively with the rate of cognition loss over time (4), and; 4) The size of the free copper pool correlates positively with the risk of conversion of patients from mild cognitive impaired status, the precursor state to $\mathrm{AD}$, to full $\mathrm{AD}$ (5). These studies tie copper toxicity closely to the pathogenesis of loss of cognition in AD.

Additionally a paper by James et al (6) shows copper toxicity directly in the AD brain. They find what they call "labile" copper is increased in the AD brain, and causing toxicity.

A study from China is also relevant. Shen et al (7) have studied the correlation of $\mathrm{AD}$ prevalence to soil copper concentration across the provinces of China. They find the two positively correlated.

\section{Cognitive and Alzheimer's Disease-Related Toxic Effects of Inorganic Copper (Copper-2)}

In 2003 Sparks and Schreurs (8) published a groundbreaking paper which showed that trace amounts $(0.12$ ppm) of copper added to the drinking water of rabbits in a rabbit model of $\mathrm{AD}$ greatly enhanced amyloid plaque formation (one of the pathologic hallmarks in the AD brain) and memory loss. A 25 fold greater increase in food copper of the animals would have no toxic effect. This study has been amply confirmed in other AD animal models (9) and in another laboratory (10). For reference, the US Environmental Protection Agency (EPA) allows up to $1.3 \mathrm{ppm}$ copper in human drinking water, ten times the amount found toxic in AD animal models (11). In the discussion of the relevance of $\mathrm{AD}$ causation in humans by consumption of copper-2 from drinking water, the important work of Sparks and Schreurs (8) will be further discussed.
In 2006 another groundbreaking paper was published, this one by Morris et al (12). They studied nutrient intake and cognition over several years in a large Chicago population. They found that those in the highest quintile of copper intake, who were there because they ingested daily supplement pills containing copper, if they also at a high fat diet, lost cognition at six times the rate of other groups. This is extraordinary! Ingesting a pill containing copper rapidly damages cognition, and many Americans, and others in developed countries, take these multimineral pills every day. This, too, will be further discussed in more detail.

\section{Gastrointestinal Absorption of Copper-2 Versus Copper-1}

What the 2003 studies of Sparks and Schreurs (8) and the 2006 studies of Morris et al (12) had in common was that they both showed cognitive damage from ingestion of inorganic copper, which is, of course, copper-2. A good clue as to why inorganic copper might behave differently than organic copper (food copper, or copper-1) was provided in earlier copper-64 studies in WD (13). Radiolabeled copper-64, as an inorganic salt, was given orally to WD patients to see if zinc therapy was effectively blocking copper absorption. At baseline, before zinc administration, $15-25 \%$ of the radiolabel would appear in the blood 1-2 hours after being given orally, much too soon for passage through the liver. In contrast, if food copper was labeled with a longer lived radiolabel, the label wouldn't appear in the blood for 1-2 days, and then it would appear covalently bound in proteins secreted into the blood by the liver. What these studies show is that organic (food) copper is first transported to the liver, where it is put into safe channels, while a portion of inorganic copper bypasses the liver and appears immediately in the blood, adding to the free copper pool, where it is damaging to cognition.

Of course, inorganic copper is copper-2. And, as mentioned earlier, it has always been assumed that organic (food) copper is a mixture of copper-1 and copper-2, since in living tissue they form a redox doublet, catalyzing reactions critical to life. As mentioned in the Introduction, the surprising findings of Ceko et al (1) changes this assumption dramatically, and explains why radiolabeled inorganic copper and radiolabeled organic copper are absorbed so differently, as discussed above. Organic (food) copper is all copper-1, while inorganic copper is copper-2. This means that as mammals evolved they were ingesting copper-1, and weren't exposed to much copper-2. So a system evolved to safely handle copper-1, involving a specific carrier (Ctr1) (14) in the intestine, which results in routing the copper to the liver for safe handling. Exposure to copper-2 was undoubtedly quite limited until humans in developed countries started using copper plumbing and taking multimineral pills containing copper. As a consequence, there is no 
special system for safe handling of copper-2. Ctr1 can't absorb copper-2. Some copper-2 can be absorbed by the nonspecific divalent cation transporter, and some can be absorbed by diffusion. Some of this absorbed copper-2 bypasses the liver and goes immediately into the blood, as shown in the copper-64 studies mentioned earlier (13), and is toxic to cognition.

\section{The Epidemiology of Alzheimer's Disease Versus the Epidemiology of Copper-2 Ingestion in Drinking Water and Pills}

Although not everyone agrees, there is good evidence that the epidemic of AD in developed countries has only emerged over the last 100 years, and it doesn't involve undeveloped countries. That there is currently an epidemic in developed countries is clear. For example, $10 \%$ of those age 60 and over, $20 \%$ of those 70 and over, and $30 \%$ of those 80 and over develop AD in the U.S (15). These high prevalences of AD don't exist in undeveloped countries. For example, in rural India, in those age 65 and over, $\mathrm{AD}$ prevalence is $1.07 \%$ (16). As another example, in Nigeria, Africa, in those aged 65 to 74 , AD prevalence is $0.52 \%$ (17). Interestingly, in the latter study, the prevalence of $\mathrm{AD}$ in African-Americans of the same age group in Indianapolis, Indiana, USA, was 8.02\%, 15 fold higher. This great increase in AD prevalence in people of the same ethnic group in the US compared to Nigeria shows the strong effect of Westernization on increasing the prevalence.

The evidence that this epidemic, restricted to developed countries, has come on in the last 100 years, is based on the writings of various type of expert physicians in the late 1800 and early 1900s, who didn't see an AD-like dementia. For example, Osler, an internist, gathered all medical knowledge into a series of volumes, including one volume devoted to the brain, published in the late $1800 \mathrm{~s}$, and an AD-like dementia was not mentioned (18). Gowers, a neurologist, wrote a textbook of neurology in this period, and didn't mention an AD-like dementia (19). Freud, a psychiatrist, published extensively during this period, and didn't describe an AD-like dementia (20). Finally, Boyd, a pathologist wrote a textbook of pathology during this period, updated until 1938, and didn't describe the amyloid plaques and neurofibrillary tangles, hallmarks of AD brain pathology, in the brains at autopsy (21).

Some have argued that there weren't enough elderly people back then to show $A D$, since $A D$ is a disease of aging. But Waldmann and Lamb (22) showed that half the French population lived to age 60 in 1911, and the US population census in 1900 shows 3.6 million people age 60 or over, which would generate 360,000 cases at today's rate; more than enough to be seen in the clinics, and to show up at autopsy.

Others argue that people just accepted AD as a type of aging, and didn't recognize it as a special disease. This conceivably could explain the clinicians, Osler (18), Gowers (19), and Freud (20), not noting it, but it wouldn't explain Boyd (21) and other pathologists not seeing plaques and tangles at autopsy.

Some have said that perhaps the staining and other pathology techniques 100 years ago were inadequate to detect plaques and tangles. If brain autopsy material were available from, say, 1875 to 1925 , it would be valuable to restudy them with modern techniques. It would be good to settle this definitively, because if the disease was truly rare back then, it strengthens the argument that a new environmental agent, or agents, in developed countries, is responsible for the epidemic of $\mathrm{AD}$ in developed countries.

Here it will be assumed that the data supporting the idea that the epidemic of $\mathrm{AD}$ in developed countries is new (over the last 100 years) is strong, and that new environmental causative agent or agents should be rigorously searched for. Given the foregoing section on the toxicity of inorganic copper ingestion on human cognition and in AD animal models, it is reasonable to examine the hypothesis that ingestion of inorganic copper is the new key environmental factor causing the epidemic.

With this in mind, the "epidemiology" of the spread of copper plumbing in developed countries needs to be examined along side the epidemiology of the $\mathrm{AD}$ epidemic. Copper plumbing began to be used in the early 1900s, was curtailed by the two world wars, and then exploded after 1950, such that now, $80-90 \%$ of US homes have copper plumbing (23). The timing of the AD epidemic is quite similar, with a few cases appearing in the early 1900s, and then exploding after 1950 (22).

At this point it is fair to ask - does enough copper leach from copper plumbing to be potentially toxic? In a study of drinking water from 280 homes all across $\mathrm{N}$. America, it was found that about one third were over 0.1 ppm, the level toxic in animal models, about one third were below $0.01 \mathrm{ppm}$, a level deemed safe, and about one third were between 0.1 and $0.01 \mathrm{ppm}$, a level of unknown safety (24). Thus, in summary, one third to two thirds of $\mathrm{N}$ American drinking water samples were at the toxic level, or of unknown safety, if the animal models are a good guide. In conclusion, there is enough copper in drinking water in $\mathrm{N}$ America to be a major factor in causing the AD epidemic.

In regard to the hypothesis that copper from copper plumbing is a major factor in the AD epidemic, Japan provides interesting data. Japan is a developed country with a low incidence of AD (25). And Japan has shunned copper plumbing for fear of toxicity. But when Japanese migrate to Hawaii, where copper plumbing is used, their AD prevalence increases as in developed countries (26).

The other major source of copper-2 ingestion is from copper supplement pill ingestion. Most multivitamin/ multimineral and multimineral pills contain about 1.0 
mg of copper, which equals the average dietary intake of copper. Probably half the population in the U.S. and other developed countries over age 50 takes one of these pills. This great use of these supplement pills began in the last half of the 20th century, and is hypothesized here, in view of the data of Morris et al [12], to be another contributor to the $\mathrm{AD}$ epidemic.

\section{Putting it All Together}

Summarizing, there is strong evidence that the current epidemic of $\mathrm{AD}$ in developed countries is new in the sense that it has happened over the last 100 years. Probably, 100 years ago, there was an AD prevalence of $1 \%$ or so in those 60 and over in developed countries, just as there is currently in undeveloped countries. These circumstances indicate, in fact virtually "shout out", that environmental changes in developed countries are fueling the current epidemic, where prevalence has gone up to $10-20 \%$. This very likely scenario seems to have escaped the attention of the AD scientific community. There is no strong effort to find what has changed about the environment that could be causing this dramatic upsurge in $\mathrm{AD}$ prevalence. It seems likely that the views raised earlier, that the increase is due to an increasingly aged population, or AD was simply viewed as a type of senility, hold sway. The refutation of those arguments, as done here earlier, may be something the scientific community is completely unaware of.

This should change, and the search for responsible environmental agents should be pursued urgently, so that changes can be made to greatly reduce the prevalence, if possible. Here, the hypothesis that ingestion of inorganic copper is a major environmental change that is a strong factor in the epidemic of $\mathrm{AD}$ is put forward. First it was shown that AD pathogenesis is tightly linked to copper toxicity as reflected by cognition and cognition deterioration being intimately linked to the size of the blood free copper pool (2-5). The size of this pool is itself closely linked to copper toxicity in other diseases, as shown, for example, in Wilson's disease (27). Second, it was shown, that inorganic copper, copper-2, is exquisitely toxic to the brain when given in drinking water to AD animal models (8-10). Tiny amounts of copper in the drinking water, an amount so small that 25 times as much would be inconsequential if given as food copper, caused greatly enhanced AD brain pathology and memory loss. Inorganic copper, or copper-2, given as supplement pills, was extremely toxic to cognition when given to humans (12). Third, it was shown that inorganic copper given orally as copper-64, was partially absorbed directly into the blood, bypassing the liver (13), whereas food copper all passes through the liver and is put into safe channels. Fourth, understanding of the differences in absorption of inorganic copper-2 and food copper came about with the publication of Ceko et al (1), where it became known for the first time that food copper is almost all copper-1. This explains why evolution developed the Ctr1 transport system (14) that handles only copper-1, and not copper-2, and the copper- 1 ends up all going through the liver. Copper- 2 is absorbed by other systems, and some of it bypasses the liver. Fifth, and finally, it was shown that the epidemic of AD (22) closely parallels the "epidemic" of use of copper plumbing (23), except Japan, which shunned copper plumbing and has a low prevalence of AD (25). It was also shown that there is plenty of copper leached from copper plumbing to be triggering $\mathrm{AD}$, if the animal models are a good guide (24).

Another factor that may be important in causing the $\mathrm{AD}$ epidemic is a high fat diet which is, of course, associated with development, due to increased meat eating. The original AD animal model that showed the effects of small amounts of copper in the drinking water was a cholesterol-fed rabbit model (8). (Although other $\mathrm{AD}$ animal models that showed the effect of copper on the drinking water were not fed high cholesterol or high fat diets). In the work of Morris et al (12), in which the highest quintile of copper intake lost cognition at six times the usual rate, these people also ate a high fat diet. Grant (28) has shown that AD prevalence across countries is correlated with average dietary fat intake. High intake of copper and fat together may act synergistically to damage the brain. Copper is known to oxidize cholesterol and other lipids into molecules that are damaging to neurons.

There are various genetic risk factors for $A D$, such as hemochromatosis (29) and transferrin alleles (30), but these wouldn't be expected to have changed in frequency with development over the last 100 years. An interesting example of genetic risk factors is the increased frequency of certain ATP7B alleles in AD patients (31-34), suggesting that these alleles increase risk. ATP7B is the Wilson's disease gene, and when disease causing mutations are homozygous, serious copper accumulation and toxicity occur in the first two or three decades of life (27). Heterozygous carriers of one disease causing mutation have minor accumulations of copper which don't require treatment. The question is, why does homozygous Wilson's disease, with major copper toxicity, not cause cognition loss, while carriers of one Wilson's allele, with a minor extra burden of copper, appear to have an increased risk of AD? The answer might be that Wilson's disease patients are either adequately treated to eliminate the toxic free copper burden, or die, while untreated carriers expose the patient to a small amount of extra copper for a lifetime, eventually affecting cognition. So, possibly, AD can be triggered by many years of exposure to copper-2 ingestion, or to a lifetime of exposure to an extra overall copper burden.

The question can be asked, how does the copper-2 hypothesis fit into current hypotheses of AD causation? The current consensus hypothesis for AD causation 
is called the amyloid cascade hypothesis (35). In this hypothesis, a small piece of the amyloid precursor protein, called beta amyloid, is clipped off by the beta secretase enzyme. This goes on in the normal brain, but the function is unknown. In the normal brain the beta amyloid is cleared, and doesn't accumulate. In the $\mathrm{AD}$ brain, for unknown reasons, the beta amyloid accumulates and aggregates into amyloid plaques. These plaques are toxic to neurons, particularly if they bind copper on iron, in which case they give off damaging oxidant radicals. The hypothesized role of copper-2 in this scenario, is first, copper is known to stimulate the aggregation of beta amyloid into plaques (36), and second, copper binds to the plaques and makes them more toxic by causing release of oxidant radicals (37). So copper-2 is a triggering agent, enhancing beta amyloid aggregation and toxicity.

A second hypothesis for AD causation is the primary oxidant damage hypothesis (38-40). In this hypothesis, the primary event is oxidant damage (39). Beta amyloid is an antioxidant, and is made in increased amounts to be protective. The accumulating beta amyloid aggregates into plaques, but in this hypothesis, the plaques are viewed as the proverbial cart (the result) rather than the proverbial horse (the cause) (38). In this hypothesis, copper-2 could be part of the cause of the disease, causing, at least in part, the initial oxidant damage. Beta amyloid is known to reduce copper- 2 to copper- 1 , so part of its protective function could be to reduce toxic copper-2.

At this point the copper-2 hypothesis, namely that ingestion of copper- 2 is playing a very important role in triggering or causing $\mathrm{AD}$, is just that, a hypothesis. It is very well supported by the evidence, and it seems prudent to accept it simply from the standpoint that removing copper-2 ingestion is not very difficult, and if the hypothesis is correct, great benefit ensues, and there is very little cost if it turns out not to be true. So in the following section, how to stop the AD epidemic by stopping the ingestion of copper-2, is discussed.

\section{How to Stop the Epidemic of AD}

The first step is to examine the label of all supplement pills being ingested. If they contain copper, throw them out. And don't purchase supplement pills containing copper. Multivitamin pills without minerals are readily available. if a mineral is needed, such as calcium or iron, it can be taken as an individual supplement. The general population doesn't require copper supplementation. Idiopathic copper deficiency is extremely rare. There are a few types of patients (extensive gastrointestinal surgery, malabsorption syndromes, large doses of zinc) that may require copper, but they are easily identified and treated.

The second step is to test drinking water for copper levels. Avoid "first draw" water. Let the tap run five minutes before collecting the sample for testing. There are many companies that offer copper tests. If values are $0.01 \mathrm{ppm}$ or lower, it is safe. If it is over $0.01 \mathrm{ppm}$, it is not necessary to remove copper plumbing. A device, such as a reverse osmosis device, can be placed on the tap used for drinking and cooking water, and it will lower copper to safe levels. Even if copper plumbing isn't in use, it is a good idea to test the water. Sometimes source water has a high copper level.

Finally, it is probably a good idea to lower fat intake. The easiest way to do that is to lower meat intake, which is generally a healthy thing to do, because in one large study, all cause mortality was positively correlated with meat intake (41).

In conclusion, the situation with respect to the copper-2 hypothesis is much like the hypothesis that cigarette smoking causes lung cancer and cardiovascular diseases was 60-75 years ago. Those who believed the early observational data benefitted greatly from stopping, or never starting, smoking. Now, with the massive collection of ever more observational data, even the most ardent smoker is aware of the risk. The copper- 2 hypothesis, as with the smoking hypothesis, can't be finally proven by administering the putative agent to see if it causes the disease, because of ethical concerns. But if it proves to be correct, those who take the steps now to avoid copper-2 ingestion greatly decrease their risk of this very serious disease that robs the elderly of their "golden years".

Conflicts of interest: The author declares no conflict of interest

\section{References}

1. Ceko MJ, Aitken JB, Harris HH. Speciation of copper in a range of food types by x-ray absorption spectroscopy. Food Chemistry 2014;164:50-54.

2. Squitti R, Pasqualetti P, Dal Forno G, Moffa F, Cassetta E, Lupoi D, et al. Excess of serum copper not related to ceruloplasmin in Alzheimer disease. Neurology 2005;64:1040-6.

3. Squitti R, Barbati G, Rossi L, Ventriglia M, Dal Forno G, Cesaretti S, et al. Excess of nonceruloplasmin serum copper in AD correlates with MMSE, CSF [beta]-amyloid, and h-tau. Neurology 2006;67:76-82.

4. Squitti R, Bressi F, Pasqualetti P, Bonomini C, Ghidoni R, Binetti G, et al Longitudinal prognostic value of serum "free" copper in patients with Alzheimer disease. Neurology 2009;72:50-5.

5. Squitti R, Ghidoni R, Siotto M, Ventriglia M, Benussi L, Paterlini A, Magri M, Binetti G, Cassetta E, Caprara D, Vernieri F, Rossini PM, Pasqualetti P. Value of serum nonceruloplasmin copper for prediction of mild cognitive impairment conversion to Alzheimer disease. Ann Neurol 2014;75:574-580.

6. James SA, Voritakis I, Adlard PA, Duce JA, Masters CL, Cherny RA, Bush AI. Elevated labile $\mathrm{Cu}$ is associated with oxidative pathology in Alzheimer disease. Free Radic Biol Med 2012;52:298-302.

7. Shen XL, Yu JH, Zhang DF, Xie JX, Jiang H. Positive relationship between mortality from Alzheimer's disease and soil metal concentrations in mainland China. J Alzheimers Disease 2014

8. Sparks DL, Schreurs BG. Trace amounts of copper in water induce betaamyloid plaques and learning deficits in a rabbit model of Alzheimer's disease. Proc Natl Acad Sci USA 2003;100:11065-9.

9. Sparks DL, Friedland R, Petanceska S, Schreurs BG, Shi J, Perry G, et al. Trace copper levels in the drinking water, but not zinc or aluminum, influence CNS Alzheimer-like pathology. J Nutr Health Aging 2006;10:247-54.

10. Singh I, Sagare AP, Coma M, Perlmutter D, Gelein R, Bell RD, Deane RJ, Zhong E, Parisi M, Ciszewski J, Kasper RT, Deane R. Low levels of copper disrupt brain amyloid-beta homeostasis by altering its production and clearance. Proc Natl Acad Sci USA 2013;110:14471-14476.

11. National Research Council. Copper in Drinking Water 2000.

12. Morris MC, Evans DA, Tangney CC, Bienias JL, Schneider JA, Wilson RS, et al. Dietary copper and high saturated and trans fat intakes associated with 
cognitive decline. Arch Neurol 2006;63:1085-8.

13. Hill GM, Brewer GJ, Juni JE, Prasad AS, Dick RD. Treatment of Wilson's disease with zinc. II. Validation of oral 64 copper with copper balance. Am J Med Sci 1986;292:344-9.

14. Ohnik H, Thiele DJ. How copper transverses cellular membranes through the copper transporter 1, Ctrl. Annals of the New York Academy of Sciences 2014;1314:32-41.

15. Alzheimer's Association. Alzheimer's Disease Facts and Figures 2010;1-74.

16. Chandra V, Ganguli M, et al. Prevalence of Alzheimer's Disease \& Other Dementias in Rural India. Neurology 1998;51:1000-1008.

17. Hendrie H, Osuntokun O, et al. Prevalence of Alzheimer's Disease and Dementia in Two Communities: Nigerian Africans and African Americans. Am J Psychiatry 1995;152:1485-1492.

18. Osler W. Modern medicine in theory and practice. Philadelphia and New York: Lea and Febiger 1910.

19. Gowers WR. A manual of diseases of the nervous system. Philadelphia: P Blakiston, Son, and Co 1888.

20. Strachey J, Freud A, Strachey A, Tyson A. 24 volumes entitled, the standard edition of the complete psychological works of Sigmund Freud, written between 1895 and 1939. London: The Hogarth Press and the Institute of Psycho-Analysis 1966.

21. Boyd WA. Textbook of pathology: an introduction to medicine. Philadelphia: Lea and Febiger 1938.

22. Waldman M, Lamb M. Dying for a hamburger: modern meat processing and the epidemic of Alzheimer's disease. 2005.1st US ed New York: Thomas Dune Books/St Martin's Press.

23. Foley PT. International Copper Demand Patterns - The Case of Plumbing Tube, CRU Consultants Inc., New York, NY, Economics of Internationally Traded Minerals, Economics of Copper, 1995; Section 5.2, 183-186.

24. Brewer GJ. Copper excess, zinc deficiency, and cognition loss in Alzheimer's disease. Biofactors 2012;38:107-113.

25. Ueda K, Kawano H, Hasuo Y, Fujishima M. Prevalence and etiology of dementia in a Japanese community. Stroke 1992;23:798-803.

26. White L, Petrovitch H, Ross GW, Masaki KH, Abbott RD, Teng EL, et al. Prevalence of dementia in older Japanese-American men in Hawaii: the Honolulu-Asia Aging Study. J Am Med Assoc 1996;276:955-60.

27. Brewer GJ. Wilson's disease In Harrison's Principles of Internal Medicine, 17th Edition. Fauci AS, Braunwald E, Kasper DL, Hauser SL, Lango DL, Jameson JL, Loscalzo J (Eds). McGraw-Hill Companies, Inc, New York 2008.

28. Grant WB. Dietary links to Alzheimer's disease. Alzheimers Dis Rev 1997;2:42-55.

29. Moalem S, Percy ME, Andrews DF, Kruck TP, Wong S, Dalton AJ, et al. Are hereditary hemochromatosis mutations involved in Alzheimer disease? Am J Med Genet 2000;93:58-66.
30. Zambenedetti P, De Bellis G, Biunno I, Musicco M, Zatta P. Transferrin C2 variant does confer a risk for Alzheimer's disease in caucasians. J Alzheimers Dis 2003;5:423-7.

31. Bucossi S, Polimanti R, Mariani S, Ventriglia M, Bonvicini C, Migliore S, Manfellotto D, Salustri C, Vernieri F, Rossini PM, Squitti R. Association of K832R and R952K SNPs of Wilson's disease gene with Alzheimer's disease. J Alzheimers Dis 212;29, 913-919.

32. Bucossi S, Polimanti R, Ventriglia M, Mariani S, Siotto M, Ursini F, Trotta L, Scrascia F, Callea A, Vernieri F, Squitti R. Intronic rs2147363 variant in ATP7B transcription factor-binding site associated with Alzheimer's disease. J Alzheimers Dis 2013;37, 453-459.

33. Squitti R, Polimanti R, Bucossi S, Ventriglia M, Mariani S, Manfellotto D, Vernieri F, Cassetta E, Ursini F, Rossini PM (2013) Linkage disequilibrium and haplotype analysis of the ATP7B gene in Alzheimer's disease. Rejuvenation Res 2013;16, 3-10.

34. Squitti R, Polimanti R, Siotto M, Bucossi S, Ventriglia M, Mariani S, Vernieri F, Scrascia F, Trotta L, Rossini PM. ATP7B variants as modulators of copper dyshomeostasis in Alzheimer's disease. Neuromolecular Med 15, 515-522.

35. Hardy J, Selkoe DJ. The amyloid hypothesis of Alzheimer's disease: Progress and problems on the road to therapeutics. Science 2002;297:353-356.

36. Sarell CJ, Wilkinson SR, Viles JH. Sub-stochiometric levels of copper ions accelerate the kinetics of fibre formation and promote cell toxicity of amyloid beta from Alzheimer's disease. J Biol Chem. 2010;285, 41533-41540.

37. Sayre LM, Perry G, Harris PL, Liu Y, Schubert KA, and Smith MA. In situ oxidative catalysis by neurofibrillary tangles and senile plaques in Alzheimer's disease: a central role for bound transition metals. J Neurochem 2000;74, 270-279.

38. Lee H-G, Castellani RJ, Zhu X, Perry G, Smith, MA. Amyloid-B in Alzheimer's disease: the horse or the cart? Pathogenic or protective? Intl J of Exp Pathol 2005;86:133-138.

39. Nunomura A, Tamaoki T, Motohashi N, Nakumura M, McKeel Jr DW, Tabaton M, Lee H-g, Smith MA, Perry G, Zhu X. The earliest stage of cognitive impairment in transition from normal aging to Alzheimer's disease is marked by prominent RNA oxidation in vulnerable neurons. J Neuropathol Exp Neurol 2012;71:233-241.

40. Schrag M, Muellar C, Zabel M, Crofton A, Kirsch WW, Chribi O, Squitti R, Perry G. Oxidative stress in blood in Alzheimer's disease and mild cognitive impairment: a meta-analysis. Neurobiol Dis 2013;59:100-110.

41. Sinha R, Cross AJ, Graubard BI, Leitzmann MF, Schotzkin A. Meat intake and mortality: a prospective study of over half a million people. Arch Int Med 2009;167:562-571. 